\title{
Perfil dos Catadores frente à Política Nacional de Resíduos Sólidos: O caso do Lixão de Iguatu
}

\author{
Anny Kariny Feitosa ${ }^{1}$; Mônica Maria Siqueira Damasceno ${ }^{2}$; Priscila Gonçalves Marinho ${ }^{3}$; Kevin Brasil da Silva ${ }^{4}$
}

Resumo: A aprovação da Política Nacional de Resíduos Sólidos - PNRS estabelece diretrizes relativas à gestão integrada e ao gerenciamento de resíduos no Brasil, tendo o catador como um ator importnte na coleta dos materiais reutilizáveis e recicláveis, com gestão compartilhada entre poder público e sociedade civil. O presente projeto teve como objetivo identificar o perfil socioeconômico de catadores atuantes no município de Iguatu. Para tanto, foi realizada pesquisa bibliográfica e entrevistas aplicadas a 22 catadores que atuam no lixão do município de Iguatu. Como resultados, encontrou-se que $86 \%$ dos entrevistados são do sexo feminino, reconhecem- se como de cor parda, e alegam que não possuem o ensino fundamental completo. Sobre a renda, $55 \%$ informaram que percebem renda inferior a 1/2 salário mínimo. Todos os consultados são beneficiados do programa Bolsa Família e $77 \%$ recebem ainda a dedução referente à tarifa social de energia elétrica (baixa renda). Quando questionados sobre o desejo de retomar os estudos, 50\% demonstram interesse, além de manifestarem o desejo de ampliar o conhecimento e de auxiliar os filhos nos processos de aprendizagem escolar. Sobre a Política Nacional de Resíduos Sólidos, todos os participantes mencionaram não possuir conhecimento da existência desta política, nem sabiam precisar o papel do catador neste processo. Foi observado que não existe apoio na formação destes atores por nenhuma instituição. Assim sendo, urge a necessidade da formulação de programas que oportunizem a estes agentes o desenvolvimento das competências necessárias para atuarem nos termos da PNRS.

Palavras-chave: Catadores; Perfil Socioeconômico; Política Nacional de Resíduos Sólidos

\section{The Profile of Collectors facing the National Policy on Solid Residues: The landfill case in Iguatu}

\begin{abstract}
The approval of the National Solid Waste Policy - NSWP establishes guidelines for the integrated management and residue management in Brazil, with the collector as a key player in the collection of reusable and recyclable materials, with shared management between government and civil society . This project aimed to identify the socioeconomic profile of active collectors in the city of Iguatu. Therefore, bibliographical research and interviews applied to 22 pickers working at the landfill in the city of Iguatu. As a result, it was found that $86 \%$ of respondents are female, know themselves as mulatto, and claim that have not completed primary education. On income, $55 \%$ reported that they perceive income of less than half the minimum wage. All respondents are beneficiaries of the Bolsa Família program and 77\% still receive the deduction on the social tariff for electricity (low-income). When asked about the desire to return to school, 50\% show interest, and expressed their willingness to expand knowledge and to assist children in school learning processes. About the National Policy on Solid Residues, all participants mentioned not have knowledge of the existence of this policy, did not know precisely the role of the collector in this process. It was observed that there is no support in the formation of these actors by any institution. Therefore, there is urgent need for programs formulation oportunizem these agents of development of skills necessary to work under PNRS.
\end{abstract}

Keywords: Collectors; Socioeconomic Profile; National Solid Waste PolicyPalavras

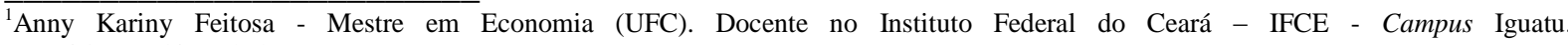
anny.feitosa@ifce.edu.br

${ }^{2}$ Mônica Maria Siqueira Damasceno - Mestre em Saúde da Criança e do Adolescente (UECE). Docente no Instituto Federal do Ceará - IFCE - Campus Juazeiro do Norte. siqueiramonica@ hotmail.com

${ }^{3}$ Priscila Gonçalves Marinho - Assistente Social no Instituto Federal do Ceará - IFCE - Campus Iguatu. priscila.marinho@ifce.edu.br

${ }^{4}$ Kevin Brasil da Silva - Graduando em Tecnologia em Irrigação e Drenagem pelo Instituto Federal do Ceará - IFCE - Campus Iguatu. kevinbrasil_tid@yahoo.com.br
} 


\section{Introdução}

Com o advento da aprovação da lei 12.305, de 02 de agosto de 2010, que institui a Política Nacional de Resíduos Sólidos - PNRS (BRASIL, 2010) e estabelece diretrizes relativas à gestão integrada e ao gerenciamento de resíduos, promove-se a inclusão e integração dos catadores de materiais reutilizáveis e recicláveis com gestão compartilhada entre poder público e sociedade civil.

Neste sentido, a PNRS tem como destaque a inserção do conceito de responsabilidade compartilhada, o incentivo ao desenvolvimento de cooperativas ou de outras formas de associação de catadores como forma de uma ação socioambiental.

Entretanto, a criação e a plena efetivação da responsabilidade compartilhada pelo ciclo de vida dos produtos, de forma individualizada e encadeada, envolvendo fabricantes, importadores, distribuidores, comerciante, poder público e consumidores nas várias cadeias de produção e consumo, são um grande desafio para a implementação da PNRS. Outro ponto importante é a inserção da participação efetiva dos catadores nas ações de responsabilidade compartilhada, conforme um dos objetivos da PNRS descritos no Art. $7^{\circ}$, inciso XII da Lei 12.305/2010.

Parafraseando Gonçalves (2005), a partir do ano 2002, a ocupação de catador de material reciclável foi incluída na Classificação Brasileira de Ocupações - $\mathrm{CBO}$, sendo atribuições deste profissional: catar, selecionar e vender materiais, como papel, papelão e vidro, bem como, materiais ferrosos e não ferrosos e outros materiais reaproveitáveis. Contudo, o catador ainda é considerado inútil para grande parcela da sociedade, bem como aqueles que trabalham com o lixo são associados a sua matéria prima e recebem, também, os seus estigmas.

Não obstante esta realidade social, os principais mecanismos de operacionalidade da PNRS priorizam a participação e a atuação estratégica e incisiva dos catadores de resíduos e suas cooperativas. Inegavelmente, a PNRS e sua regulamentação trouxeram grandes desafios aos catadores de materiais reciclados, que precisarão mudar os modelos atualmente adotados para o êxito de sua implementação, por não estarem, em sua maioria, organizados para assumir tal incumbência. Inclusive, por falta de conhecimento da existência da legislação e de outras políticas públicas de gestão de resíduos sólidos.

São diversos os desafios enfrentados pelos catadores de materiais reciclados no modelo de gestão de resíduos sólidos, definido pela Lei Federal 12.305/2010 e que veio a ser regulamentado pelo Decreto Federal 7404/2010, consolidando papéis extremamente importantes para as cooperativas de reciclagem, onde seu envolvimento e comprometimento poderão determinar o êxito da implementação da PNRS. 
Deste modo, com base no tema abordado, formulam-se as questões norteadoras para o presente estudo: Qual o perfil socioeconômico dos catadores de resíduos sólidos atuantes no município de Iguatu? Tais catadores estão preparados para atuar nos termos da PNRS?

\section{Revisão da Literatura}

A reciclagem é tida como a recuperação dos materiais descartados, modificando suas características físicas, diferenciando-as de reutilização, em que os descartados mantêm suas feições. Embora polua menos o ambiente e envolva menor uso de matérias-primas virgens, água, e energia, como processo "final" para o tratamento de resíduos.

Para a Organização Não Governamental "Compromisso Empresarial para Reciclagem" (CEMPRE, on line), a reciclagem de materiais pode ocorrer sem a separação prévia de resíduos nas fontes geradoras. Num programa de coleta seletiva, a própria comunidade contribui separando resíduos nos domicílios e estabelecimentos, e alguns funcionários que concluem esta separação, sem necessidade de maquinário especial, numa central de triagem.

Os resíduos que podem ser reciclados em classificação simples são: o papel, o metal, o plástico e o vidro. As vantagens ambientais da reciclagem destes materiais comparadas ao processo de produção a partir de matéria prima virgem passam pela redução do uso de energia e de água, poluição da água e do ar.

O equacionamento da problemática do lixo depende da criação de políticas públicas específicas, como uma Política Nacional de Resíduos Sólidos. Segundo Jacobi et. al. (2006) o Brasil tem multiplicado as experiências de gestão compartilhada de resíduos sólidos por meio de programas municipais de coleta seletiva em parceria com catadores organizados e autônomos.

O primeiro projeto de coleta seletiva do Brasil, foi criado em São Paulo, com a tentativa de efetuar a inclusão social de catadores, no qual foi iniciada a primeira Cooperativa dos Catadores de Papel, Aparas e Materiais Reaproveitáveis - Coopamare, em 1989, estimulada pela Igreja (Pastoral da Rua) e movimentos sociais.

Em 2000, a partir do Fórum Lixo e Cidadania, surgiu o Movimento Nacional dos Catadores de Materiais Recicláveis, que conforme aponta Jacobi et. al. (2006), culminou no reconhecimento do trabalho do catador, sendo incorporado ao Código Brasileiro de Ocupações - CBO, que classifica as diversas atividades dos trabalhadores do País, nos mais diferentes setores de atividade, tanto do setor

público como privado. É também o documento que reconhece, nomeia e codifica os títulos e descreve as características das ocupações do mercado de trabalho brasileiro. Sua atualização e modernização se 
devem às profundas mudanças ocorridas no cenário cultural, econômico e social do País nos últimos anos, implicando alterações estruturais no mercado de trabalho.

De acordo com Jacobi et. al. (2006), a temática que envolve os resíduos sólidos "exemplifica a formulação de políticas públicas que promovem mudanças nos hábitos e atitudes dos cidadãos, com o objetivo de minimizar ou prevenir a degradação ambiental".

A aprovação da lei 12.305, de 02 de agosto de 2010, que institui a Política Nacional de Resíduos Sólidos - PNRS (BRASIL, 2010), estabelece diretrizes relativas à gestão integrada e ao gerenciamento de resíduos sólidos prevendo a implantação de coleta seletiva com a inclusão e integração dos catadores de materiais reutilizáveis e recicláveis com gestão compartilhada entre poder público, sociedade civil. Citados os caminhos legais e sociais acerca da problemática em torno dos resíduos sólidos tem-se a coleta seletiva como estratégia de ação e o catador como um ator de grande importância na coleta dos resíduos sólidos urbanos.

A PNRS tem como principais pontos de inovação a inserção do conceito de responsabilidade compartilhada, reconhecendo a necessidade de participação de todos os elos da cadeia, o incentivo ao desenvolvimento de cooperativas ou de outras formas de associação de catadores como forma de uma ação socioambiental, bem como traz o conceito da logística reversa.

A criação e a plena efetivação da Responsabilidade Compartilhada pelo ciclo de vida dos produtos, de forma individualizada e encadeada, envolvendo fabricantes, importadores, distribuidores, comerciante, Poder Público e consumidores nas várias cadeias de produção e consumo, são um grande desafio para a implementação da PNRS. A Lei Federal 12.305/2010 define que:

Art. $3^{\circ}$. Para os efeitos desta Lei, entende-se por: [...] XVII - responsabilidade compartilhada pelo ciclo de vida dos produtos: conjunto de atribuições individualizadas e encadeadas dos fabricantes, importadores, distribuidores e comerciantes, dos consumidores e dos titulares dos serviços públicos de limpeza urbana e de manejo dos resíduos sólidos, para minimizar o volume de resíduos sólidos e rejeitos gerados, bem como para reduzir os impactos causados à saúde humana e à qualidade ambiental decorrentes do ciclo de vida dos produtos, nos termos desta Lei.

Outro ponto importante da PNRS é a inserção da participação efetiva dos catadores nas ações de responsabilidade compartilhada, conforme um dos objetivos da PNRS descritos no Art. $7^{\circ}, \S$ XII da Lei 10.305/2010: "São objetivos da Política Nacional de Resíduos Sólidos [...] integração dos catadores de materiais reutilizáveis e recicláveis nas ações que envolvam a responsabilidade compartilhada pelo ciclo de vida dos produtos".

Tanto a PNRS quanto sua regulamentação, por meio do Decreto Federal 7.404/2010, asseguram aos catadores formas de melhorias em suas atividades, conforme segue: 
Art. 44. As políticas públicas voltadas aos catadores de materiais reutilizáveis e recicláveis deverão observar:

I - a possibilidade de dispensa de licitação, nos termos do inciso XXVII do art. 24 da Lei $n^{\circ}$ 8.666, de 21 de junho de 1993, para a contratação de cooperativas o associações de catadores de materiais reutilizáveis e recicláveis;

II - o estímulo à capaticapão, à incubação e ao fortalecimento institucional de cooperativas, bem como à pesquisa voltada para sua integração nas ações que envolvam a responsabilidade compartilhada pelo ciclo de vida dos produtos; e

III - a melhoria das condições de trabalho dos catadores.

Parágrafo único. Para o atendimento do disposto nos incisos II e III do caput, poderão ser celebrados contratos, convênios ou outros instrumentos de colaboração com pessoas jurídicas de direito público ou privado, que atuem na criação e no desenvolvimento de cooperativas ou de outras formas de associação de catadores de materiais reutilizáveis e recicláveis, observada a legislação vigente.

Não obstante, a PNRS e sua regulamentação trouxeram consigo grandes desafios, exigências e necessidade de adequação para os catadores de materiais recicláveis, tais como: adequações legais, o licenciamento ambiental, a adoção de boas práticas, a realização de capacitações, bem como a criação de novos modelos de administração e operacionalização das cooperativas para atendimento da volumosa demanda de resíduos a serem coletados seletivamente para produção em grande escala.

\section{Material e Métodos}

Conforme Marconi e Lakatos (2006) a metodologia é a explicação minuciosa, detalhada, rigorosa e exata de toda a ação desenvolvida no método de trabalho da pesquisa. É a explicação do tipo de pesquisa, do instrumental utilizado, do tempo previsto, da equipe de pesquisadores e da divisão do trabalho, das formas de tabulação e tratamentos de dados.

De acordo com Alvarenga (2010, p. 61), "o desenho metodológico constitui o plano da investigação, como se colocará em prática o estudo. Orienta a investigação, contem as estratégias a serem seguidas para dar resposta ao problema formulado, alcançar os objetivos e comprovar a hipótese".

O presente trabalho foi elaborado utilizando-se de pesquisa bibliográfica sobre o objeto de estudo, através de coleta de dados em livros, revistas especializadas, artigos científicos e bancos de dados científicos disponíveis na Internet. Além disso, constou de um estudo de caso, com um enfoque quantiqualitativo que, conforme Gil (2007), consiste em um estudo profundo que permite um amplo e detalhado conhecimento do objeto estudado.

Alvarenga (2010, p. 9,10) diz que o enfoque quantitativo trabalha com amostras probabilísticas, cujos resultados têm possibilidade de generalizar a população em estudo e o paradigma qualitativo tenta descrever e compreender as situações e os processos de maneira integral e profunda, considerando inclusive o contexto que envolve a problemática estudada. 
A população de catadores informais do lixão da cidade de Iguatu - CE é de aproximadamente 50 pessoas. A pesquisa aconteceu por meio da realização de entrevistas semiestruturadas envolvendo 22 catadores atuantes no referido município, durante o segundo bimestre de 2014, utilizando o seguinte procedimento metodológico: identificação de campo de pesquisa, coleta de dados e tabulação dos resultados.

Salienta-se que a pesquisa seguiu obedecendo à Resolução do Conselho Nacional de Saúde, que faz referência às diretrizes e normas regulamentadoras de pesquisa/estudos que envolvam seres humanos (BRASIL, 2012).

\section{Resultados e Discussões}

A apresentação dos resultados está estruturada em tópicos, visando facilitar a leitura de aspectos considerados pertinentes na caraterização do perfil do catador em estudo.

\section{Identificação}

Dentre os catadores entrevistados, estão $86 \%$ mulheres e $14 \%$ homens. De acordo com Martins (2005), as mulheres geralmente são responsáveis pelas atividades que exigem maior concentração e motricidade fina, como a limpeza do local de trabalho, triagem de materiais. Os homens, por sua vez, desempenham predominantemente funções que exigem ou são relacionadas à força física, como o transporte de material e manejo de máquinas pesadas.

Observa-se que a faixa etária dos catadores está compreendida com idades entre 20 e 49 anos. De acordo com os dados da pesquisa, $85 \%$ dos entrevistados declararam ter cor parda, $5 \%$ cor negra, $5 \%$ cor amarela, $5 \%$ cor amarela e $5 \%$ cor branca.

\section{Situação Familiar}

Todos os catadores entrevistados são chefes de família, ou seja, trabalham para manter todas as despesas da casa. Pode-se constatar que $86 \%$ dos entrevistados têm filhos e $14 \%$ não tem filhos.

Em relação ao estado civil dos entrevistados, $41 \%$ são solteiros, $36 \%$ têm união estável, $18 \%$ são casados e 5\% são divorciados.

No questionamento sobre a família dos catadores que moram na mesma residência $32 \%$ dos entrevistados responderam que a família é composta por 6 pessoas, $18 \%$ por 5 pessoas, $9 \%$ com 4 e 2 pessoas, $1 \%$ com 1 pessoa e $0,5 \%$ com 8 e 7 pessoas. 


\section{Trabalho e Renda do Catador}

Dos sujeitos da pesquisa, a maioria, que totaliza 55\%, recebem até $1 / 2$ salário mínimo, $41 \%$ até 1 salário e $4 \%$ de 1 a 2 salários mínimos. Este indicativo demonstra que 96\% dos catadores auferem renda inferior a 1 salário mínimo, atuando especificamente como catador, o que pode impactar na qualidade de vida destes trabalhadores dada a restrição orçamentária.

De acordo com os dados, observa-se que todos os entrevistados recebem o benefício da bolsa família e 77\% recebem ainda a dedução referente à tarifa social de energia elétrica (baixa renda).

\section{Moradia}

Dos entrevistados, $73 \%$ possuem casa própria, $23 \%$ alugada e $4 \%$ cedidas. Estes indicativos demonstram que mesmo os catadores tendo uma renda familiar baixa, a maioria possui casa própria.

\section{Escolaridade}

Dados da pesquisa revelam que apenas 5\% dos entrevistados possuem nível médio completo, enquanto $9 \%$ possuem nível médio incompleto, $27 \%$ fundamental completo, $50 \%$ fundamental incompleto e $9 \%$ dos sujeitos não são alfabetizados. Como pode ser percebido, a maioria dos entrevistados alegam não possuir o ensino fundamental completo e, segundo relatos, não desenvolvem atualmente nenhuma atividade de âmbito educativo.

Quando questionados sobre o desejo de retomar os estudos, 50\% demonstram interesse, além de manifestarem o desejo de ampliar o conhecimento e de auxiliar os filhos nos processos de aprendizagem escolar.

\section{Sobre a Política Nacional de Resíduos Sólidos}

Quando perguntados a respeito da Política Nacional de Resíduos Sólidos, todos os participantes mencionaram não possuir conhecimento da existência desta política, nem sabiam precisar o papel do catador neste processo. Além disso, foi observado que não existe apoio na formação destes atores por nenhuma instituição. 


\section{Considerações Finais}

Esta pesquisa apresentou dados e impressões preliminares no estudo do perfil socioeconômico da população de catadores de resíduos sólidos, atuantes na cidade de Iguatu, Ceará.

Um dos dados da entrevista que chamou a atenção foi o fato de nenhum dos participantes possuir conhecimento sobre a Política Nacional de Resíduos Sólidos, o que nos faz acreditar que também desconhecem a importância do papel que desempenham na sociedade, bem como os seus direitos, por meio da atuação em associações e cooperativas.

A partir da análise das narrativas construídas durante as entrevistas e dos dados disponíveis, considera-se oportuno encerrar esta pesquisa trazendo uma provocação sobre a necessidade da formulação de programas que oportunizem a estes agentes o desenvolvimento das competências necessárias para atuarem nos termos da PNRS.

\section{Referências}

ALVARENGA, E. M. Metodologia da Investigação quantitativa e qualitativa: normas técnicas de apresentação de trabalhos científicos. Gráfica Fas. Assunção-PY, 2010.

ASSMANN, H. Reencantar a Educação. Rumo à sociedade aprendente. Petrópolis, RJ: Vozes, 2003.

BRASIL. Lei no 8.742, de 7 de dezembro de 1993. LOAS - Lei Orgânica da Assistência Social.

BRASIL. Lei no 12.305, de 2 de agosto de 2010, que institui a Política Nacional de Resíduos Sólidos.

BRASIL. Decreto Federal no 7.405/2010 - Institui o Programa Pró-Catador.

BRASIL. Ministério da Saúde. Secretaria de Ciência, Tecnologia e Insumos Estratégicos. Departamento de Ciência e Tecnologia.Capacitação para Comitês de Ética em Pesquisa CEPs/Ministério da Saúde/Ministério da Saúde, Secretaria de Ciência, Tecnologia e Insumos Estratégicos, Departamento de Ciência e Tecnologia. - Brasília : Ministério da Saúde, 2012.

CEMPRE (on line). Compromisso Empresarial para Reciclagem. Disponível em: <http://www.cempre.org.br/>. Acesso em: 224 abr 2014.

DRIMER, Alícia e DRIMER, Bernardo. Las cooperativas escolares. 3 ed. Intercoop: Buenos Aires, 1987.

FERRINHO. Homero. Educação cooperativa. Lisboa Livraria Popular: Francisco Franco, 1985.

FREIRE, Paulo. Ação cultural para a liberdade. 10 ed., Rio de Janeiro: Paz e Terra. 2002.

FREIRE, Paulo. Pedagogia do oprimido. 50 ed. Rio de Janeiro: Paz e Terra, 2011. 
GIL, Antonio Carlos. Como elaborar projetos de pesquisa. 4 ed. São Paulo: Atlas, 2007.

GOHN, M. G. Educação não-formal e cultura política: impactos sobre o associativismo do terceiro setor. São Paulo: Cortez, 2005.

GONÇAlveS, R. C. M. A Voz dos Catadores de Lixo em sua Luta Pela Sobrevivência (Dissertação). Mestrado em Políticas Públicas e Sociedade. UECE: Fortaleza, 2005. Disponível em: $<$ http://www.uece.br/politicasuece/index.php/arquivos/doc_view/52-

ubiacristinamartinsgoncalves 1 ?tmpl=component\&format=raw >. Acesso em: 24 abr 2014.

GUATTARI, Félix. As três ecologias. Campinas. 11 ed. SP: Papirus, 2001.

JACOBI, P. et al. Gestão compartilhada dos resíduos sólidos no Brasil. São Paulo:

Annablume, 2006.

LÉVY, P. A Inteligência Coletiva. Por uma antropologia do ciberespaço. Tradução de Luiz Paulo Rouanet. 5. ed. São Paulo: Edições Loyola, 2007.

LIBÂNEO, J. C. Pedagogia e pedagogos, para quê? São Paulo: Cortez, 2005.

MARCONI, M.A; LAKATOS, E. M. Técnicas de Pesquisa. 6. ed. São Paulo: Atlas, 2006.

MARTINS, C.HB. Catadores/Reciladores na Região Metropolitana de Porto Alegre: organização do trabalho e identidade profissional. Mulher e Trabalho, Porto Alegre, v.5 p65-78, 2005.

MARQUES, M. O. Educação/interlocução, aprendizagem/reconstrução de saberes. Ijuí: Editora UNIJUI, 1996.

SCHNEIDER, J. O. Democracia, participação e autonomia cooperativa. São Leopoldo, UNISINOS, 1999.

SEVERINO, A. J. Educação e ética no processo de construção da cidadania. In: LOMBARDI, J. C. e GOERGEN, P. (orgs.). ética e educação: reflexões filosóficas e históricas. Campinas, SP: Autores Associados, 2005.

Como citar este artigo (Formato ABNT):

FEITOSA, A.K.; DAMASCENO, M.M.S.; MARINHO, P.G.; SILVA, K.B. O Perfi dos Catadores frente à Política Nacional de Resíduos Sólidos: O caso do Lixão de Iguatu. Id on Line Revista de Psicologia, Fevereiro de 2015, vol.9, n.25, p. 217-225. ISSN 1981-1189. 